MISCELÁNEA 



\title{
Dios, el mundo y el hombre según Ramon Llull*
}

\author{
God, the world and the man according to Ramon Llull
}

\author{
Fernando Domínguez Reboiras \\ Universidad de Freiburg im Breisgau
}

La tarea que me he propuesto en esta intervención es resumir a través de los conceptos Dios, mundo y hombre el pensamiento luliano tal y como él lo fue expresando en los miles de páginas que dejó escritas. Dada la brevedad de tiempo y la dimensión del intento sé muy bien que ésta es una tarea problemática y casi imposible. Al final de este esfuerzo de síntesis puede ser que logre un importante objetivo y es que Vds. se den cuenta de la profundidad e importancia del discurso luliano.

La primera obra del largo catálogo luliano es un compendio de lógica, tal vez un libro de ejercicios escolares que Llull escribió durante una primera fase de intensos estudios. Al final de este opúsculo, se lee una frase que puede servir de programa para toda su obra: «De lògica parlam tot breu / car a parlar avem de Déu».

Jordi Gayà, a quien mucho debemos todos los que estudiamos la obra luliana, no se cansa de repetir que en la mayor parte de sus obras Ramon Llull trata temas que corresponden al ámbito de la teología y, más concretamente, a la exposición de la doctrina cristiana tal como viene expresada en el símbolo de la fe. Cito a Gayà:

Los escritos lulianos deben ser considerados como un corpus teológico en sentido estricto, en el que, por supuesto, tienen cabida, como también sucede en otros autores de la Edad Media, escritos dedicados a temas que una más moderna división de las ciencias ha excluido de la teología.

En efecto, Ramon escribe, casi exclusivamente, sobre temas teológicos, aunque de una forma original pues lo hace siempre a partir del método y de la doctrina de su Arte y no con el vocabulario usado por los teólogos de su tiempo.

\footnotetext{
* «Dios, el hombre y el mundo según Ramon Llull», Dijous, 26 de febrero 2015: Conferència inaugural del Cicle de conferències en Homenatge a Ramon Llull en el VII Centenari de la seva mort, organizados por la Reial Acadèmia mallorquina d'estudis històrics, genealògics i heràldics (Palma de Mallorca).
} 
Esto puede parecer hoy algo nuevo e inaudito, pero los que saben algo de filosofía saben bien que desde los comienzos de la reflexión filosófica en Grecia y, por lo menos, hasta Hegel la filosofía occidental fue esencialmente teología. El mismo Hegel, que aprendió a filosofar en el Evangelischer Stift, aún hoy un centro teológico protestante de Tubinga, hablando de la relación entre filosofía y teología dejó caer aquella famosa frase: «Der Inhalt ist dasselbe». Es decir, el contenido de ambas ciencias es el mismo.

Pero si Dios fue el tema más importante de la reflexión filosófica -incluso allí donde se afirma la incognoscibilidad de Dios - y si ese tema proporciona a la filosofía occidental hasta bien entrado el siglo XIX una cierta unidad, sería ingenuo, e incluso erróneo, no reconocer la diversidad de la noción de Dios. Los filósofos cuando hablan de Dios no están hablando del mismo Dios. Se podría ir más allá y afirmar que la diferencia específica entre los sistemas filosóficos es su noción de Dios.

El discurso luliano de Dios parte de unos postulados gnoseológicos admitidos en su entorno. A Dios no lo vemos, ni lo oímos, ni lo olemos, ni lo gustamos, ni lo podemos tocar. Dios, si existe, es algo o alguien que está fuera del alcance de nuestros sentidos. Pero ¿cómo podemos llegar a conocerlo, si nuestro entender sólo puede realizarse a través de los cinco sentidos? Si admitimos, aunque sólo sea hipotéticamente la existencia de Dios, tenemos que admitir que el conocimiento de una realidad espiritual, es decir, de algo que está evidentemente fuera del ámbito material e inmediato de nuestra sensualidad, tiene que ser algo singular incomparablemente diverso a todo conocimiento sensorial. Aquí radica el profundo dilema de todo discurso sobre Dios. Si hablamos de Dios tenemos que hablar en términos distintos a todo discurso que no sea Dios. El discurso religioso que admite la existencia de Dios como algo real porque sí, porque se cree en él, tiene que ir por otros caminos que el discurso científico apoyado en el entender a través de las cinco ventanas por donde entra y se inicia todo conocimiento humano.

Pero ¿cómo llega al conocimiento de Dios el hombre religioso? En el judaísmo, el cristianismo y el islam, aquellas que Mahoma llamó «religiones del libro», la respuesta es sencilla y decisiva: En un momento concreto de la historia humana Dios se comunicó al hombre. Estas tres religiones tienen pues en común la inaudita pretensión de su origen. La fe de estas tres religiones se funda en la revelación divina, hecho fundamental y decisivo en su ideario religioso: En la conciencia religiosa de millones de creyentes Dios habló in illo tempore, de una vez para siempre, por motivos y procedimientos diversos. El resultado de este proceso son los textos sagrados guardados con celo por la comunidad de creyentes. Si Dios ha hablado, el hablar humano sobre Dios sólo puede ser coherente desde la palabra revelada por Dios. La grandeza y, al mismo tiempo, la causa del enorme poder de convicción de estas religiones es precisamente esta primera y originaria creencia: Dios y no el hombre es la fuente de toda verdad. La verdad es un regalo de Dios no una conquista intelectual del hombre.

Pero ¿qué queremos decir cuando decimos con tanta naturalidad algo tan difícil de creer como que lo que está escrito en un libro humano es palabra de 
Dios? Para alguien como Ramón que vive en un ambiente cultural en el que conviven tres religiones la cuestión se complica. La palabra de Dios escrita que aceptan los judíos es también palabra de Dios para los cristianos que añaden un grupo de escritos más que los judíos no aceptan. La palabra de Dios escrita que aceptan los musulmanes no rechaza la Biblia de cristianos y judíos sólo apunta que ha venido del cielo una nueva palabra que sustituye definitivamente todas las revelaciones anteriores. A esto se arrima un segundo problema que se centra en el credo de la cristiandad que desde sus nuevos escritos presenta a un Dios que entra en la historia del hombre manifestándose trinitariamente como Padre, Hijo y Espíritu Santo y no exclusivamente a través de la palabra escrita, sino a través de la palabra hecha carne humana («el Hijo, el Verbo de Dios, o sea, la palabra de Dios, se hizo carne y habitó entre nosotros»). Esta visión de un Dios, diferenciado en tres personas, supone para las otras dos religiones, deshacer la profunda e inmutable creencia común en un Dios único.

En este sentido bien entendía Llull que todas las religiones son, en cierto modo verdaderas, pues ayudan y nos dan la pauta y el guión para hablar de Dios, para dar ese paso inicial en el conocimiento de la divinidad. Llull acepta que los libros sagrados nos dan un material teológico imprescindible, pero las diferencias entre ellos nos obligan a pensar que tiene que haber una instancia por encima de esos libros para conocer la verdad sobre Dios. Por eso parte él del simple supuesto que Dios habla siempre y a todos.

La revelación y la venida de esa palabra de Dios en un tiempo concreto de la historia no excluye que Dios nos esté hablando constantemente a través de otros medios, y si se quiere, a través de otros libros. Si Dios es amor y por amor nos creó, está claro que nos está enseñando constantemente esa su condición de amador. Si de algo está seguro Ramon Llull es justamente de este amor universal, incondicional y sin restricciones del Dios cristiano. Por eso antes que Dios se manifestase a través de los profetas, no estuvo callado y sus criaturas no podían ignorar su amor y sus obras. En este contexto Ramón no rechaza el contenido de los libros sagrados de las tres religiones pero se da perfecta cuenta que una discusión entre creyentes arrimando cada uno sus textos sagrados no conduce a ninguna parte. Sería una discusión interminable. Llull le llama a esta discusión una disputa «per auctoritates». Por eso propone él un diálogo interreligioso basado en otras manifestaciones de Dios. El cree en otra revelación evidente, universal y ubicua desde el comienzo mismo de la humanidad. No rechaza la palabra de Dios revelada in illo tempore y guardada en los libros, pero deja claro que hay otra instancia para ir hablando de Dios. La revelación contenida en los libros sagrados fue importante para activar una reflexión más profunda, pero toda persona que piense y reflexione tiene que admitir que Dios no sólo se ha comunicado a través de un libro, sino que toda la creación, como obra de Dios, es un libro abierto que no necesita palabras y está cantando las maravillas de su hacedor.

Cuando Ramón habla de un nuevo libro para convertir a los infieles está pensando en un libro que ponga de manifiesto la realidad divina no en contra pero sí al margen de los libros sagrados de cada religión. Él bien sabía que los mismos libros sagrados afirman unísono la realidad de ese otro «libro». Así, por 
ejemplo, la Biblia hebrea dice (Eccl 17, 6-8): «Les formó boca y lengua y ojos y oídos y mente para entender; los colmó de inteligencia y sabiduría y les enseñó el bien y el mal; les mostró sus maravillas, para que se fijaran en ellas... les concedió inteligencia»). Más claro San Pablo en su Epístola a los Romanos: «Porque lo que puede conocerse de Dios lo tenemos a la vista, Dios mismo nos lo ha puesto delante; desde que el mundo es mundo, lo invisible de Dios, es decir, su eterno poder y su divinidad, resulta visible para el que reflexiona sobre sus obras...» (Rom 1, 19-20). Las citas bíblicas y coránicas en este sentido son numerosas.

Para Llull está claro que Dios se manifiesta al mundo desde la creación del mundo. Y esa creación no fue un acto inicial aislado donde Dios dijo: ¡Ahí te quedas, apáñate! El Dios creador que él propone es un Dios que crea por amor y actúa por amor constantemente. En consecuencia el producto de esa creación es algo llamado a conocer y amar a su creador. Todo lo que ha creado Dios está cantando y dando señales de la acción constante creadora de Dios. El acto de magnanimidad divina de darle ser al mundo no supone un punto final en la operación creativa de Dios. El carácter dinámico de la acción causal divina se extiende a los efectos de esa acción, es decir, el carácter dinámico de la misma creación se extiende hasta sus más pequeños elementos. La creación no fue un acto inicial acabado, todo lo contrario, Dios está continuamente creando y el mundo está reproduciendo, como en un espejo, esa acción continua. Por eso nada está ocioso en el mundo.

Para explicar este difícil traspaso de la estructura divina activa a las criaturas utiliza Llull como ejemplo las propiedades de los elementos que son así una reproducción del obrar trinitario: El fuego tiene que quemar necesariamente, sino no es fuego, si ese fuego calienta agua o tierra, eso es algo contingente. Es decir, el fuego es «substancial» y «propiamente» activo en su entraña, en sí mismo, caliente o no algo externo a él.

La religión que presente un concepto de Dios más racional y convincente, que dé de Dios una noción más perfecta y coherente con la realidad que habla a través de las obras de Dios, ésa será la religión más verdadera. Acentúo lo de «más verdadera» porque Ramón no dirá que las otras religiones son falsas, sino sólo menos verdaderas. Aquí está un pilar de su teología y la base de toda su argumentación. Aquella religión que presente el mejor Dios (el Deus maior, en expresión luliana) es la verdadera pues da razón del Dios verdadero y ese Dios verdadero se ha de mostrar como lo máximo que de él pueda ser pensado.

La teología de Llull es, por otra parte, una filosofía de la limitación humana, de la constitutiva incapacidad del hombre en llegar a un conocimiento de Dios. Porque nuestro entendimiento humano y limitado no puede conocer a Dios, como él es. El único conocimiento posible de la divinidad es una búsqueda, es ir ascendiendo hacia él siguiendo las huellas que va dejando el Creador en las cosas visibles. A través de su creación vamos descubriendo la bondad, la grandeza, el poder y los demás atributos o dignidades divinas.

Está claro que partiendo de estos postulados la teología luliana y su consecuente cosmovisión no se diferencia de los presupuestos doctrinales de su épo- 
ca, ya que toma como punto de partida el hecho indiscutible del mundo como producto de la creación, es decir, la división de la realidad en dos partes: Dios creador y la realidad por Dios creada. Dios lo crea todo según sus dignidades, es decir, Dios y sus dignidades son la causa y el arquetipo de las cosas creadas, las cosas son, pues, semejanzas de las dignidades divinas. Los diferentes modos de realizarse las dignidades como principios de todo lo creado sirven para establecer una jerarquía en la realidad que expresa una diferenciación ontológica según se aleja de la perfección absoluta del Creador. Esta diferenciación progresiva descendente (descensus) es la que sirve de guía al conocimiento de toda la realidad y el camino inverso (ascensus) es guía para conocer a su Creador. Desde el Libre de contemplació hasta el final de su incansable tarea de escritor, pasando por todas las extensas formulaciones de su Arte general, se esfuerza Llull en mostrar ese ascensus como fundamento y base de una verdadera ciencia fundada en la razón y no en una opinión recibida a través de una fe heredada $\mathrm{y}$ intelectualmente no asimilada.

En resumidas cuentas, conocemos el sentido y razón de ser de todas las cosas a través de Dios pero, a su vez, ese Dios sólo puede ser conocido a través de las cosas. La manifestación de los atributos divinos en el mundo por él creado es la base de toda ciencia, de todo conocimiento, de todo entender. Dios actuando a través de sus dignidades nos ofrece los principios por los que llegamos a conocer todo lo que puede ser conocido por la razón humana. Los principios del Arte luliano son esas dignidades o atributos divinos, por eso el Arte ofrece una lectura perfecta de todo el universo y también la base para todas las ciencias particulares. En el Ars generalis ultima lo expresa Llull con meridiana claridad:

El entendimiento humano se apoya más bien en opiniones que no en fundada ciencia, y esto es así porque cada ciencia tiene sus propios principios que no concuerdan con los principios de las otras ciencias, por eso el entendimiento siente la imperiosa necesidad y desea ardientemente una ciencia general a todas las ciencias. Una ciencia general con principios generales, en los cuales estén implícitos y contenidos los principios de las otras ciencias particulares, así como lo particular está contenido en lo universal... Quien conozca esta ciencia podrá aprender más fácilmente las otras ciencias, pues los principios particulares se reflejan y manifiestan en los principios generales de esta ciencia o arte de la misma forma que la parte está contenida en el todo.

Cada una de sus dignidades son propiedades de Dios, son «propias» de Dios y principios de toda acción sea ésta en la esencia del mismo Dios o en sus operaciones fuera de su íntimo ser trinitario. La vida en Dios es fuente y principio de toda vida, afirmación actual y plenaria de su primitiva unidad. Ser uno no es simple negación de división sino actividad unificante. Dios es uno cuando unifica, bueno cuando bonifica, grande cuando engrandece, etc. Dios es unidad, bondad, grandeza fontal. Por eso todo lo que hay en las criaturas se debe a la presencia en ellas de esos atributos divinos. Comprender, conocer ese proceso íntimo de Dios significa para Llull comenzar a comprender y a saber todo lo 
referente al mundo y a las criaturas que sólo se pueden comprender partiendo de ese hondo conocimiento de la interna perfección activa de la esencia divina.

En su peculiar lenguaje artístico expone Llull como el ser de Dios, en su íntima realidad, es un ser efusivo. Dios es fecundidad infinita. Esta efusión tiene lugar en su propia vida personal, se proyecta exteriormente creando las cosas y se da a sí mismo en la encarnación para asociar la creación a su propia vida personal. Dios es acto puro gracias a la trinidad de personas y sólo puede ser acto puro si hay trinidad de personas. Las tres no hacen sino expresar de un modo completo y claro que Dios es pura acción interminable y perfecta. A la efusión interna trinitaria se sigue la efusión creadora por la que Dios produce las cosas. Como consecuencia de esta creación en la que se crean cosas distintas a Dios exige la voluntad divina la deificación de esa creación. En esa deificación o encarnación Dios se da personalmente a sí mismo logrando una unificación de las creaturas en la vida personal de Dios. En la trinidad Dios vive, en la creación produce cosas, en la encarnación las eleva para asociarlas a su vida personal. Para eso hace Dios de una naturaleza creada, el hombre, la naturaleza de su propio ser personal. Esta unidad personal es Cristo y por medio de Cristo los demás hombres obtienen una participación en la vida personal de Dios. Aunque la encarnación se realiza en la creatura hombre, la creación en su totalidad no es ajena a este proceso de deificación y se integra en ella a través del hombre. Por eso la encarnación se presenta como objetivo melior et maior de la creación. Cristo es maior finis mundi, ratio essendi, dignitas mundi y exaltatio mundi.

Llull va desarrollando este fundamental ideario cristológico como manifestación del amor de Dios para mostrar así la concordancia suma entre Dios y las criaturas. Para que esa deificación sea total tiene que incluir, además del mundo espiritual, necesariamente el mundo corporal para que Dios mejor pueda comprehendere omnia (reunir en sí todas las cosas). La encarnación es así una altior et nobilior communitas, es decir, el justo orden y la justa comunidad entre Dios y las criaturas.

Detrás de toda esta intuición inicial y profunda está la indiscutible y necesaria unión del entendimiento de la naturaleza y el entendimiento de Dios. Una separación de estos dos «entenderes» es para Llull inadmisible. Todo se entiende en esa dependencia porque estaba convencido que la presencia de la naturaleza en Dios y la presencia de Dios en la naturaleza se correspondían en un único acto de entender. Por eso entender a Dios comenzaba por entender la naturaleza pues sin ese paso inicial sería todo conocimiento humano una inútil tarea.

Si todo es así como él lo ve, no es extraño que, después de este fervor especulativo, Llull se queje repetidas veces de la falta de conciencia y falta de entusiasmo por parte de los cristianos que no interiorizan esta maravillosa realidad. Se asombra como los cristianos no han comprendido esta maravilla y por eso no saben exponer a los infieles estas cosas tan hermosas que forman, para él, la entraña de la concepción cristiana de Dios. Misión no significa para Llull proselitismo barato sino mostrar aquel concepto cristiano de Dios que él abraza y que tiene que entusiasmar a toda persona que lo comprenda así. Se extraña 
Ramón de la falta de fieles amadores que propaguen con entusiasmo la bondad, la grandeza, la belleza del Dios cristiano a aquellos que no han oído de sus maravillas. Los cristianos están obligados a explicar y exponer a los otros creyentes la belleza de un Dios más grande que aquel en el que los otros creen. El ardor misionero luliano viene exigido por la hondura e interno engranaje del concepto cristiano de Dios que él ve mucho más profundo que el Dios de las otras religiones. Su intención es hacer llegar ese Dios cristiano a los que creen de una manera más imperfecta en ese mismo Dios. Trinidad y encarnación son señal de la superioridad del concepto cristiano de Dios y la exacta interpretación de lo que tiene que ser el Dios verdadero, es decir, responde a las exigencias que impone la razón al concepto de ser supremo trascendente y, por ello, también expresión de la superioridad de la ley cristiana frente a las otras formas religiosas.

Así, según él, viven los musulmanes bajo una lex falsa (no del todo conforme con la razón pues no acepta las consecuencias que se siguen razonablemente del concepto de Ser supremo) y son, por eso, infideles. Se trata de una infidelidad a los principios de la razón que no puede aceptar tal deficiencia en su concepto de Dios. Para Ramon Llull los musulmanes tienen una visión de Dios estática. Dios es, para ellos, un ser distante e inactivo, donde el amor de Dios hacia los hombres no tiene espacio ni lugar. Aquí se muestra, según él, la deficiencia fundamental del concepto de Dios propagado por Mahoma y extendido en el Islam. Los musulmanes hablan de un Dios que es, pero nada hace, no actúa. La falta de consideración intelectual y reflexión racional sobre la unidad divina les lleva a creer que el Dios uno de los cristianos eternamente activo en sí mismo a través de las tres personas de la trinidad no es otra cosa que un burdo e inadmisible triteísmo. Llull pretenderá demostrar que todo el discurso trinitario cristiano sobre paternidad, filiación y espiración en Dios, bien entendido, no tiene que estar reñido con el primer y fundamental dogma coránico. Llull propone un discurso sobre la necesidad de admitir la trinidad divina en Dios partiendo de la indiscutible verdad de la necesaria actividad interna en la unidad divina. Llull habla de un Dios uno que incluye necesariamente el ser trino.

En todo este engranaje teológico se inserta una concepción del hombre sumamente original. ¿Qué pinta el ser humano en el conjunto de la creación? El hombre es una substancia compuesta en el que están presentes constitutivamente ambas partes de la realidad, la corporal y la espiritual. En su aspecto corporal el hombre queda constituido a partir de la composición elemental por las potencias o naturalezas vegetativa, sensitiva e imaginativa. La composición del cuerpo humano supone, sobre todo, una comunidad del hombre con la realidad elemental, vegetal y animal. La parte más amplia en todas las disquisiciones antropológicas lulianas la constituye, sin embargo, el estudio de las «tres potencias, que son de la esencia del alma racional», memoria, entendimiento y voluntad. Sobre ellas se construye en gran parte el Ars luliana. No nos podemos adentrar aquí en el desarrollo de su psicología, sin duda un importante capítulo y clave de su sistema.

Así como la realidad humana es el eslabón donde se encuentran los dos aspectos de la realidad (lo corporal y lo espiritual), así también el conocimiento 
que tiene el hombre de sí mismo le abre el camino para el conocimiento de toda la realidad. El sujeto hombre es la llave para conocer el mundo, porque el ser humano es la síntesis de toda la realidad visible.

En todas las reflexiones lulianas sobre el hombre está la profunda convicción de la nobleza y dignidad del ser humano que Llull no se cansa de describir como «maior pars mundi», la obra más noble e importante de toda la creación. Si hay una idea que se puede decir que recorre todas las páginas del gran Libre de contemplació en Deu y también en su novela Félix o Libro de las maravillas, es precisamente ésta: la alta nobleza y dignidad que Dios de manera graciosa y magnánima concedió al hombre, a la que éste tiene que responder debida- y libremente. A lo largo de estos libros exalta y alaba Ramón al creador de todas las cosas con profunda reverente gratitud por haber creado y exaltado lo más grande y granado de sus obras: el ser humano. Sin denigrar ni disminuir la superioridad ontológica de los entes puramente espirituales, afirma sin ambages que el ser humano es el ser más noble después de Dios. Sí, para él el hombre es superior a los ángeles.

Llull habla del hombre como una figura central dentro del universo creado, relacionado con todos los seres inferiores y superiores, admirando la compleja estructura de su naturaleza como un puente entre el mundo físico y el espiritual. El hecho de que el cuerpo humano esté formado con los mismos elementos de los otros cuerpos del mundo visible crea una realidad común y una participación de la que, entre los seres espirituales, sólo el alma participa plenamente. Complejo y maravilloso es el ser humano por ese complejo y maravilloso cuerpo que el alma con sus tres potencias, memoria, entendimiento y voluntad, dignifica y hace participe con el mundo espiritual.

Pero la fundamental estructura racional de la naturaleza humana no implica la demonización del cuerpo en la tradicional expresión espiritualista (neo)platónica. Para Ramón el cuerpo es una parte constitutiva del hombre de gran importancia porque establece la base de su esencial relación con el resto del mundo físico. Esto le impide aceptar una pura y dura explicación espiritualista de ser humano. Por eso el alma, según él, no puede ser una simple substancia inmaterial separada del cuerpo al que accidentalmente está ligada. La interna y profunda conjunción de las dos partes está en contradicción con un dualismo que pretende ver esa unión como algo accidental o externo sin unidad esencial y substancial.

$\mathrm{Ni}$ el cuerpo solo, ni el alma separada son el hombre entero. El cuerpo y el alma son partes integrantes de la esencial estructura del hombre. Todo el mundo en el entorno luliano diría esta frase: «El alma está en el cuerpo del hombre» pero sólo Llull termina la frase así: «y el cuerpo del hombre está en el alma, de modo que una parte del todo está en la otra, para que de ambas sea compuesto el todo».

El alma, pues, es sólo «alma humana» cuando está unida al cuerpo. El ser humano ha de ser definido en su totalidad, no sólo en su parte espiritual sino tambien en su parte corporal. 
El hombre se constituye cualitativamente como figura clave y fundamental en el centro del universo creado. Esta privilegiada posición es consecuencia de la equilibrada conjunción del cuerpo humano (la más perfecta estructura dentro del mundo físico) con las tres potencias del alma que le dan vida y, a la vez, con clara opción y participación en el mundo espiritual. El hombre se constituye en la entidad más importante de la creación gracias a su entitativa participación en las perfecciones de los escalones inferiores del mundo corporal que entran a través de él en comunión con el mundo espiritual. El discurso luliano sobre el hombre se concentra más en la determinación y consideración del puesto clave de la especie humana en la escala de las criaturas y su especial relación con la totalidad del universo creado.

Aunque Dios es el fin y causa final de toda la creación, éste fin no puede ser alcanzado plena y permanentemente por las criaturas no racionales. Esa incapacidad es constitutiva y se debe al simple hecho de que Dios es invisible y no puede ser visto, oído ni tocado y que no hay cuerpo o cosa en este mundo que pueda «recordar, entender y amar a Dios». Aunque todo cuerpo tenga una apetencia natural y un constitutivo anhelo de servir a Dios, pues para eso fue creado, necesita del ser humano para que el mundo material pueda ser divinizado. Para Llull, el alma humana, por su participación constitutiva en el cuerpo humano,

[...]es medio e instrumento por el qual las criaturas corporales, esto es, el cielo y los otros cuerpos que en si contiene, alcancen el fin à que son creadas; el qual fin es Dios, que creo todos los cuerpos para que le sirvan.

El alma racional, en función de su carácter espiritual y de sus potencias espirituales, da al hombre la posibilidad de realizar esa singular, imprescindible y soberana función dentro de la creación. Esa importante y vicaria tarea de mediación entre los seres corporales y espirituales que Llull concede al hombre no puede ser cumplida por ninguna otra criatura espiritual, como pudieran ser los ángeles, que, al ser puros espíritus, no están unidos a una realidad corporal:

Por ello es conveniente que exista una substancia espiritual unida al cuerpo humano, que llamamos alma racional para que las criaturas corporales tengan un fin en el que puedan tener su descanso.

Llull llega a afirmar que, si solamente existiesen en la creación substancias corporales y espirituales y no hubiese una substancia compuesta de cuerpo y espíritu, habría un «vacuo en el ordenamiento del acto creativo, y habría dos extremos sin mediación posible «. Este orden en la creación exige necesariamente ese ser compuesto de substancia corporal y espiritual.

Esa importante función que se concede al hombre dentro de la creación no es sólo motivo de honor y gloria sino una importante tarea y obligación moral frente al mundo no racional que no es obstáculo sino enorme ayuda en su camino hacia Dios, afirmando que el falso uso que hace el hombre de la materia es causa de todos los males y del pecado. No iríamos por ello muy equivocados, si intentamos espigar textos lulianos para una teoría ecológica del hombre como responsable de la naturaleza. 
La fascinante originalidad del discurso luliano sobre el hombre radica en el hecho de ser Ramon Llull el primer pensador medieval que considera la humanidad en ella misma y en su valor propio. Por razones apologéticas trata Llull la realidad humana por encima de la definición teológica de los estados del hombre que era el punto de partida de toda reflexión en el entorno intelectual luliano. Esa reflexión se movía entre dos extremos, de un lado la doctrina del pecado original, que postula una corrupción radical de la naturaleza humana, y del otro la grandeza del hombre hecho a imagen y semejanza de Dios. Llull, en cambio, propone una reflexión del hombre sobre sí mismo, sobre los «misterios y virtualidades del hombre mismo» (secreta et naturae sui ipsius).

La novedad luliana de centrar sus reflexiones sobre el hombre en su naturaleza dinámica de mediador entre el mundo corporal y espiritual no está fundamentado, como ya se ha dicho, en razones estrictamente filosóficas, sino, como todo proceder luliano, por razones apologéticas, es decir, por su ideario misional. El discurso sobre un hombre (Adán) caído es un discurso de autoridad fundado en la historia bíblica. La búsqueda de un discurso racional sobre el hombre, al margen de los libros sagrados, le lleva a considerar la perfección natural del hombre como hombre en su triple potencial anímico ubicado en la realidad de su cuerpo elementado. Con sobriedad, claridad y firmeza traslada la consideración soteriológica del hombre fundamentándola en su desnuda naturaleza creada. Así supera Ramón el clásico discurso teológico cristiano sobre el hombre. El ser humano no está encuadrado en dos representaciones antitéticas: dignidad y miseria, hombre viejo y hombre nuevo, hombre pecador y hombre redimido. Llull en su pasión apologética se percata de que la teología no ofrece una síntesis del hombre porque supone una dualidad que impide al hombre comprenderse a sí mismo, su naturaleza genuina, lo que él es, sus «secreta» (arcana interioridad) y sus «naturae» (sus virtuales posibilidades). La dualidad, la división, la lucha entre los dos extremos se traslada al campo de la moral, pero una moral racionalizada en el discurso sobrio de la relación antitética entre las virtudes y los vicios. En el plano ontológico es la posición privilegiada del hombre como maior pars mundi (la parte más granada del mundo) indiscutible e irrefutable.

Llull exalta la naturaleza intelectual del compuesto humano no para separarlo de su raíz corporal, sino para resaltar su dependencia con el mundo físico que le determina como el ser capaz de integrar todo el universo en su finalidad espiritual. La idea de perfección humana no puede ser desarrollada desde la vigente mentalidad teológica agustiniana, donde toda perfección humana pasa necesariamente por una creación dañada y caída «per peccatum Adae». En su sistemática búsqueda de un sistema liberado de autoridades logra Ramón liberar el concepto de hombre de toda disquisición teológica fundamentada en presupuestos bíblicos y crear una ciencia sobre el hombre fundada en el hombre mismo, en el estudio de su naturaleza, sin autoridad bíblica alguna.

En razón de su estructura dinámica, ese hombre, creado a imagen y semejanza de Dios tiene pues, como ya hemos visto, la clara función de ser el vínculo de unión entre el mundo material y espiritual. Por eso la clásica definición del hombre como animal rationale no reúne, para Llull, las condiciones de una 
definición exhaustiva. En contra de toda la tradición filosófica define él al hombre como animal homificans. La definición homo animal rationale es parcial pues atiende sólo a la parte racional del hombre. La actividad fundamental de ser humano tiene como objetivo prioritario la perfección de su especie que es constitutivamente materia y espíritu.

Como Dios sólo es Dios trinitariamente, haciéndose Dios, el hombre sólo es hombre haciéndose hombre (homificans), en ese irse haciendo hombre y cuanto más hombre más perfecto para alcanzar y comprender el ser humano su específico modo de ser. Esa comprensión, ese saberse hombre, es el comienzo y fin de toda actividad humana.

Pues es bien verdad, que si el hombre tiene un gran placer en conocer lo escondido y las posibilidades de otros seres, cuánto mayor será su placer en conocer los misterios y virtualidades encerradas en él mismo.

El pensamiento luliano libre de autoridades y de magisterio escolar, libre también de la tutela clerical, es una ciencia que, aunque Llull, no la llevó a sus últimos extremos filosóficos, abría un horizonte insospechado. Aquel horizonte que los humanistas supieron traducir en un nuevo concepto de libertad de estudio e investigación. Libertad no significa ya que el hombre ha recibido de la naturaleza un ser cierto y terminado que va llevando de alquiler a través de su vida, sino algo que se alcanza, se supera y se realiza en un continuo hacer, hacerse y superarse. De ahí aquel homo est animal homificans que en traducción muy libre podríamos transcribir así: el hombre ha recibido un alma (racional), es decir, es un ser animado que (conscientemente) vive (en un proceso) homificante (porque es) homificable (es decir perfeccionable) para continuamente homificarse a sí mismo y a los demás seres corporales y para humanizarse más a sí mismo y humanizar el mundo que le rodea.

La enigmática definición luliana (homo animal homificans) expresa que el ser humano es actividad y sus actos (como en Dios) no consisten sino en volver a sí mismo. La propia y positiva constitución interna es reflejo del ser trinitario divino. Su ser consiste en llegar a ser lo que él es, aquello que es su íntima y radical entidad como maior pars mundi.

A través de la razón, a fuerza de pensar, vino a ver Ramón como necesario el camino de Dios al hombre, la encarnación de Dios, como un camino hacia la luz, es decir, la visión comprensiva exhaustiva y total de la esencia de la humanidad. Pero ese camino de Dios al hombre es un camino de ida y vuelta, es decir, hay que hacer también el camino del hombre a Dios o, más exactamente, al hombre divinizado. Lo más impresionante de este proceso es que, sólo él, considera que los sentidos corporales no son obstáculo sino órganos sensores del absoluto. La antropología luliana es, por ello, teología, y más concretamente cristología. La realidad humana se explica y se aclara en su relación con la divinidad. Consecuentemente lo que sabemos o podemos pretender saber de Dios sólo es posible a través de la inmediata realidad de nuestra humanidad. El hombre es así la única instancia capaz de hacerse comprender como microcos- 
mos abarcando por sí misma y en sí misma la realidad material y espiritual de la que — gracias a Dios (y más concretamente gracias a Dios hecho hombre)— es partícipe.

***

Hace siete siglos que murió Ramon Llull. Un abismo de tiempo separa su mundo del nuestro. Si nos preguntamos que nos puede él enseñar, la respuesta no es fácil. Pero creo que algo puede apuntarse después de estas reflexiones.

En el pensamiento luliano no hay lugar a biparticiones o compartimentos indivisibles e incomunicables. El amor aparece siempre como razón de ser y última instancia. Desde su conversión Llull se propone ser un amador y por encima de todo extender ese amor que el concebía activo y brotando en la misma entraña del ser. En su tiempo, como en el nuestro, ideologías, visiones del mundo, filosofías y teologías se enfrentaban y actuaban con el único objeto de someter, esclavizar o aniquilar al enemigo. Mientras esas opiniones enfrentadas no buscaban más que la derrota del otro y no se esforzaban por buscar sus comunes raíces y resolver sus comunes problemas no podía llegar la paz entre los pueblos y las religiones. Llull, obsesionado por la unidad y la concordia, no ofrecía una solución definitiva de todos los problemas que aquejaban a la humanidad y tampoco un remedio milagroso que lograse, por arte de magia, una concordia inmediata. Pero, cuanto más penetramos en su obra, entendemos mejor que aquello que él pretendía era lograr que hombres de diferente origen luchasen por unirse en un programa de futuro común sin sacrificar su razón y renunciar a su libertad. La dinámica de su pensamiento tiende claramente a unir, a limar todas las diferencias que separaban a los hombres de su época. No se puede alinear a Llull entre los pensadores que pretenden separar y dividir: La vida no estaba limitada al mundo vegetal, a los animales o al compuesto humano. En la materia descubre y resalta la activa fuerza de los elementos y sus combinaciones para mostrar que nada, ni siquiera las piedras, están inactivas. Y por encima de la realidad cósmica distinguía él formas diversas de actividad espiritual: una unida a las impresiones de los sentidos y de la imaginación y otra liberada de esas ataduras; una que aceptaba creyente la manifestación de Dios a través de su palabra y otra que se identificaba con ella entendiéndola. Pero para Llull esas dobles realidades no se excluyen: ni el ser y el pensar, ni la materia y el espíritu, ni la realidad sensual o intelectual, ni la realidad finita y eterna están en oposición sino unidas en una misma realidad comprensible por la fe y la razón.

Está claro que Ramon Llull es un ejemplo a seguir en la aceptación radical del otro. Nada existiría para Llull sin la pluralidad, sin la diversidad de colores, sonidos, lenguas, religiones, razas... La aceptación de esa condición del ser es constitutiva de todo su pensamiento y es por ello que su pensamiento se puede ofrecer como punto de partida y ejemplar diseño de un diálogo productivo dentro de la diversidad de culturas.

La unión del entendimiento del cosmos con el entendimiento de la realidad divina era también el camino real para lograr todo lo que parecía imposible. La 
división entre los hombres, sobre todo las diferencias entre gentiles, judíos, cristianos y musulmanes serían así franqueables. Las verdades escritas en el libro sagrado de cada confesión o creencia no podían conducir a una concordia. Cada una de esas creencias se fundamentaba en una palabra de Dios, que los otros no reconocían como tal. Por eso los hombres estaban necesariamente obligados a hacer uso de aquello que era común a todos, la razón humana y aprender a comprender todo «de modo natural». Por eso en la filosofía luliana todo se fundamenta sobre aquello que el hombre puede llegar a comprender a la luz de su razón natural y no sobre aquello que sin fundamento racional se cree por la fe. Llull estaba convencido que no era posible llegar a comprender tanto a través de la fe como se podría llegar a comprender a través de la razón. Con esta filosofía Llull desafía a cristianos y no cristianos pues se saltaba las fronteras aceptadas hasta aquel momento entre la razón y la fe. Los problemas entre razón y fe que parecían insalvables y prejuzgaban sus contornos no son para Llull insalvables. Es más esa aparente oposición se convierte en armonía. Llull aceptaba la diferencia entre ambas pero no aceptaba las cortapisas que venía poniendo la autoridad teológica del momento. Estaba convencido que era posible y necesario demostrar con la razón natural que Dios es la expresión suma del amor en el que todo sucede y a través de quien todo sucede.

En Ramon Llull la relación es el principio de coherencia de todo su pensamiento. Todo en la realidad divina, humana y natural está íntima y necesariamente relacionado. Su teoría correlativa, fundamento y punto de partida de su Arte no tiene otro fin que expresar esa relación radical. Cualquier parcela de su pensamiento se alimenta de esa relación básica y encuentra en ella su explicación y explanación.

El núcleo y meollo del pensamiento luliano es la búsqueda, la investigación profunda de todas las conexiones y de todas las relaciones que se pueden descubrir en la realidad teológica, metafísica, antropológica, natural, ética y política. La pluralidad existe ya productiva en la misma esencia del Dios uno. Él no duda en hablar de pluralidad en Dios refiriéndose a los atributos divinos, una pluralidad que no puede estar ociosa, una pluralidad productiva. Una pluralidad relacional que se refleja y se desdobla de una manera natural en toda la producción divina creadora. La naturaleza es plural y toda obsesión de unidad y concordia ha de considerar esa primera condición. Ramon Llull afirma y recalca la diversidad como razón de ser. Los principios relativos de su arte se fundamentan en la tríada de igualdad, diferencia y concordancia. Pero lo igual, lo diferente y lo concordante no puede existir sin la condición imprescindible de una realidad plural. Una realidad plural constitutiva.

Según Ramon Llull aunque exista una unión profunda entre ser y pensar, materia y espíritu, mundo sensual y mundo espiritual, verdad sobrenatural creída y verdad natural racional cada una de esas partes tienen una existencia propia y diferencial. Y no existiría unión si no existiese la diferencia.

Por eso en 1974 el filósofo francésVladimir Jankélévitch, uno de los ideólogos del mayo del 68, dejó caer esta frase: «Ramon est le premier philosophe de la difference». Si las cosas no fuesen diferentes no podrían existir. La unidad es producto de cosas diferentes y no una amalgama indiferenciada. Por eso se ale- 
gra Llull al principio de su gran Libre de contemplació de ser como es, y da gracias a Dios por ser diferente y único, un ser singular. Y por eso la mística luliana no busca entrar y diluirse en el mar de la divinidad. Su relación con Dios es un diálogo de tú a tú. El amigo con el amado. Un diálogo profundo tiene que aceptar la diferencia y singularidad de los dialogantes. La búsqueda de la unidad, de la concordancia, no se fundamenta en la desaparición del otro, sino en un diálogo profundo y respetuoso de dos seres diferenciados y únicos. En Llull el amor se ve siempre en una articulación plural y es por eso que para el amor no es la unión el único criterio. En Ramón Llull reina siempre y se define inconfundible en todo momento la diferencia. No se trata de confundir y mezclar. Al contrario: Donde vive el amor se distingue siempre entre el amador o los amadores y el amado, y se distingue también entre el amado y el amador la realidad distinta de su amor. Los amadores no deben devorar al amado, en su amor común han de conservar tanto su personalidad de amadores y amados como aceptar su diferente condición sin mixtificaciones ni desaparición del uno en el otro. Esta afirmación de la diferencia distingue la mística luliana de toda mística de unión total y desaparición o confusión del otro en el amado. Las dos realidades no desaparecen en esa unión, sino que conservan intactas su estructura diferencial. La diferencia es su razón de ser su principio de individuación.

Llull realiza su obra a contrapelo de la época y por eso es un continuo juego de rupturas con el campo acotado de los intelectuales de oficio, una destrucción legitimada por su condición de iluminado que se afirma en cuanto excepción. Esta es la gran lección de Llull y de quienes tras él sintieron la necesidad de romper la camisa de fuerza que les oprimía, acceder a la escritura a partir de la anomalía, situarse deliberadamente al margen de las modas, corrientes y géneros, la decisión de poner en tela de juicio las formas convencionales.

La peculiar situación de Llull en el mundo de su tiempo revela en efecto su neta renuncia a toda estrategia profesional y mundana en favor de una senda propia, aislada e independiente. Él no buscaba el apoyo de la crítica oficial de su momento. Con ello contribuyó a que sus contemporáneos le consideraran, sino «loco» o fantasma, al menos como figura secundaria, un injusto papel, ese oficio de fantástico que aceptó, incorruptible, con un heroísmo sin aspavientos dejando más bien a los siglos futuros el juicio definitivo. La imagen de homo fantasticus es soberbia y cifra en su precisión la meta ascética, difícil pero asequible, de todo verdadero pensador contagiado a través de los siglos por la fecunda aventura creadora y temple moral de Ramon.

Lo que menos interesó a la masa de sus seguidores, a lo largo de los siglos, no fue el contenido de sus libros, sino el decidido enfoque de su personalidad y de su obra. Quien lo leyó, aunque supo asumir alguna de sus intuiciones, lo siguió en esa su fundamental postura de rompedor de hielos y abridor de caminos. Su ideario fundamental, sin embargo, ha quedado en el olvido. 